\title{
Fatigue Growth Behaviour of Two Interacting Cracks with Different Crack Offset
}

\author{
Huijin Jin ${ }^{1, *}$, Bing Cui ${ }^{2}$ and Ling Mao ${ }^{3}$ \\ 1 State Key Laboratory of Nonlinear Mechanics, Institute of Mechanics, Chinese Academy of Sciences, \\ Beijing 100190, China \\ 2 School of Materials Science and Engineering, Anhui University of Technology, Ma'anshan 243000, China; \\ m15901301877@163.com \\ 3 School of Materials Science and Engineering, Beihang University, Beijing 100191, China; mmlljzzx@163.com \\ * Correspondence: jinhuijin863@163.com
}

Received: 29 September 2019; Accepted: 25 October 2019; Published: 28 October 2019

check for updates

\begin{abstract}
Under cyclic fatigue load, multiple cracks would significantly deteriorate the service life of the components with respect to the case of a single crack owing to the crack interaction. The present study aims to explore the effect of crack interaction on the fatigue growth behaviour of samples with different crack offset. In this study, fatigue crack growth tests were performed for samples containing a single crack and non-collinear cracks of different crack offset in an aluminum-lithium alloy. It was shown that the two facing non-collinear cracks changed their growth direction when the cracks were overlapped, resulting in load mode transfers from mode I to I + II mixed mode. Then, the interaction behaviour was studied by establishing the finite element models to calculate the stress intensity factor $\mathrm{K}$ of samples with different crack offset. The results indicated that the $\mathrm{K}$ decreased, largely owing to the shielding effect as the two cracks overlapped, leading to retardation of crack growth in the position of overlap, especially for the specimens with a small crack offset. It was also shown that the interaction effect could change from positive to negative during the process of the multiple cracks' growth, thus leading to the acceleration or deceleration of crack growth rates, suggesting that the influence of interaction on cracks' growth behaviour could vary with the different stages of crack growth.
\end{abstract}

Keywords: non-collinear cracks; finite element analysis; fatigue crack growth; interacting behaviour

\section{Introduction}

Multiple cracks may be initiated and propagated owing to fatigue and corrosion in structural components, especially at multiple riveted locations [1-3]. During the growth process of a crack, the interaction of multiple cracks might occur when a specific condition is reached, which could have a large impact on crack growth behaviour [4,5]. The interaction might cause the increase of the crack growth rate when the adjacent cracks merge, resulting in the crack growth life being greatly reduced. Although many investigations on the influence of interaction on the cracks' growth behaviour have been conducted [4,6-11], detailed research on the effect of the interaction on multiple cracks' growth behaviour of specimens with different crack offset is very limited.

The multiple crack interactions could affect the stress fields around the crack tip, which could change the stress intensity factor $K$ on the crack tip [12,13], thus leading to the acceleration or retardation of crack growth rates. The stress intensity factor $K$ is usually calculated by the finite element method and theoretical analysis method. Han et al. [14] adopted the finite element approach to calculate the $K$ of parallel cracks, indicating that the relative positions between cracks have a great effect on the interactions. Zhao et al. [15] propose a modified analytical solution to obtain the $K$ of multiple 
hole-edge cracks. The authors introduced the approximate superposition method to add some other impacts to the equivalent crack in the complex variable function. The method showed that the modified method has good agreement with the finite element method. Jin et al. [16] proposed an improved $K$ method to study the interacting behaviour of double collinear cracks growth. The improved $K$ method was calculated using the net section stress $\sigma_{n}$ instead of the applied remote stress $\sigma$ in the equation of stress intensity factor, showing that the method could accurately describe the collinear multiple cracks growth behavior.

During the multiple cracks' growth processes, the interaction could change the crack propagation directions, thus affecting the crack propagation rates. The experimental and numerical analysis studies $[17,18]$ showed that the multiple cracks' propagation rate could be accelerated by comparing with a single crack as the neighboring cracks are merged, while the cracks may also be retardated or stationary owing to the impact of stress shielding. Also, the multi-cracks may grow under the I + II mixed mode loading condition instead of the mode I condition, because of the change of crack growth directions caused by interactions. In linear elastic fracture mechanics (LEFM), mode I and mode II are the two basic modes of crack deformation: mode I (opening), the growth directions of the crack are perpendicular to the normal stress; and mode II (sliding), the growth directions of the crack are parallel to the shearing stress. In addition, I + II mixed mode includes mode I (opening) and mode II (sliding). With the increase in the crack interactions, the extent of the cracks' deflection is increased owing to the increase of mode II [19]. However, some characteristics about crack growth deceleration have been insufficiently investigated, especially for the effect of the crack offset on multi-cracks' growth rates.

In this study, numerical computations were carried out to evaluate the stress intensity factor of interacting cracks with different crack offset. Then, the effect of cracks' interaction on the crack propagation bahaviour was studied by the fatigue crack growth tests for samples containing non-collinear cracks of different crack offset. The focus was on how the crack growth rates of samples with different crack offset were affected by crack interactions during the process of the multiple cracks' growth.

\section{Experimental Methods}

The crack propagation tests of 2060 aluminum-lithium alloy specimens with a single crack and non-collinear cracks of different crack offset were performed under the fatigue load at room temperature (297 K). The alloy had a chemical composition of $3.95 \mathrm{Cu}, 0.75 \mathrm{Li}, 0.3 \mathrm{Mn}, 0.85 \mathrm{Mg}, 0.4 \mathrm{Zn}, 0.11 \mathrm{Zr}$, $0.25 \mathrm{Ag}$, and balance $\mathrm{Al}$ in wt.\%. The crack configurations of different samples are shown in Figure 1. All samples were cut along the longitudinal (L)-transverse (T) direction. The mechanical slits were cut at the edge of the holes using wire-electrode cutting and the diameter of the molybdenum wire was $0.1 \mathrm{~mm}$. For all samples, the initial crack length of each crack was the sum of the slit length $(1 \mathrm{~mm})$, the hole diameter $(3.5 \mathrm{~mm})$, and the fatigue precracking length $(0.5 \mathrm{~mm})$.

A digitally-controlled material test system (MTS, 810, MTS Systems Corporation, Minnesota, USA) $100 \mathrm{kN}$ force cyclic test machine was used to perform the fatigue tests. The testing-frequency was $8 \mathrm{~Hz}$ and the cyclic stress ratio was $\mathrm{R}=0.1$. The maximum and minimum fatigue loads of all samples were the same, $7 \mathrm{kN}$ and $0.7 \mathrm{kN}$, respectively. To ensure the reliability of the tests, at least three identical specimens were measured for each type of sample geometry. A travelling microscope was adopted to measure the crack length in a certain cycle number. When the specimen was fractured, the fatigue tests were finished.

The tensile properties of samples were measured on the Instron 8801 type $-100 \mathrm{kN}$ testing machine Instron Corporation, Boston, UA) at a strain rate of $0.1 \mathrm{~mm} / \mathrm{min}$, and the shape and dimensions of tensile specimens are shown in Figure 2. Five tensile specimens were tested to obtain the average values of the Young's modulus E, yield strength Re, elongation $\varepsilon$, and ultimate strength Rm; these values were $74.09 \mathrm{GPa}, 480.44 \mathrm{MPa}, 15.19 \%$, and $529.7 \mathrm{MPa}$, respectively. 


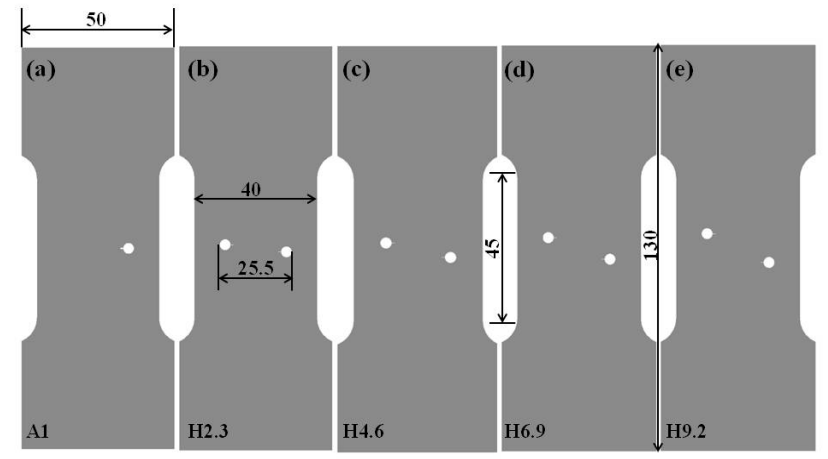

Figure 1. Sample geometry (all dimensions in $\mathrm{mm}$ ): (a) specimen A1 containing a single crack; (b) specimen H2.3 (initial condition: crack offset $\mathrm{H}=2.3 \mathrm{~mm}$ ), (c) specimen $\mathrm{H} 4.6$ (initial condition: $\mathrm{H}=4.6 \mathrm{~mm}$ ), (d) specimen H6.9 (initial condition: $\mathrm{H}=6.9 \mathrm{~mm}$ ), (e) specimen H9.2 (initial condition: $\mathrm{H}=9.2 \mathrm{~mm})$. The thickness of all specimens is $2 \mathrm{~mm}$.

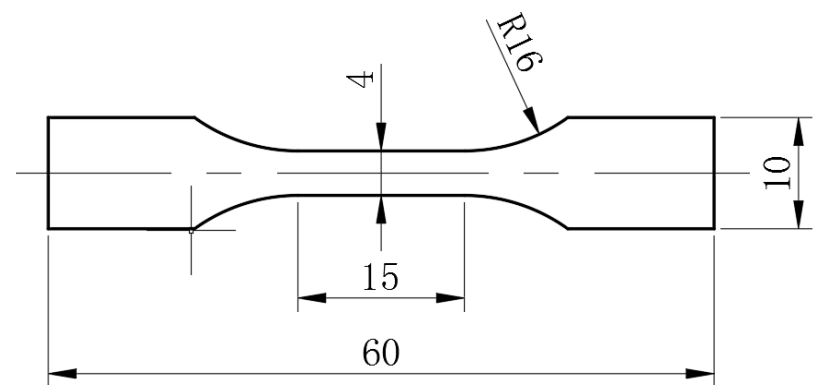

Figure 2. Shape and dimensions of tensile specimens (all dimensions in $\mathrm{mm}$ ).

\section{Finite Element Models}

The finite element models were created to numerically calculate the $\mathrm{K}$ for two interacting non-collinear cracks. The horizontal distance $S$ and crack offset $H$ were defined in Figure 3 . The plate with two through-thickness parallel cracks was subjected to the tensile loading, $\sigma_{0}$. The software ABAQUS (version 6.5, Dassault Simulia Corporation, Rhode Island, USA)) [20] was adopted to carry out the finite element analysis. The $K$ was derived from the energy release rate, which was obtained by the virtual crack extension integral method [21]. The method considers a path $\Gamma$ that encloses the crack tip and with initial and final points, which lie on the two crack faces; this integral can characterize the energy release associated with the crack growth, as follows:

$$
J=\int_{\Gamma}\left(U d y-t \frac{\partial d}{\partial x} d s\right),
$$

where $U$ is the strain energy density, $t$ the traction vector on a plane defined by the outward normal, $d$ the displacement vector, and $d s$ the element of arc along the path $\Gamma$. This integral method is used to evaluate contour integrals automatically in the finite element code ABAQUS. Therefore, the stress intensity factor $K$ is directly related to the $J$-integral, which is expressed as follows:

$$
K=\left(\frac{8 G J}{1+\kappa}\right)^{1 / 2}
$$

where $G$ is the shear modulus, $\mathrm{k}$ is a function of Poisson's ratio, $\kappa=(3-v) /(1+v)$ in plane stress state, $\kappa=3-4 v$ in plane strain state and $v$ is the Poisson's ratio. To confirm of the accuracy of $K$, a relatively fine mesh was adopted on the crack tip. An example of the finite element mesh for a type of crack geometry is presented in Figure 4. The mesh contains approximately 16,292 eight-noded solid elements for the crack geometry of $S=15.5 \mathrm{~mm}, \mathrm{H}=2.3 \mathrm{~mm}$, and $2 \mathrm{a}=5 \mathrm{~mm}$. 


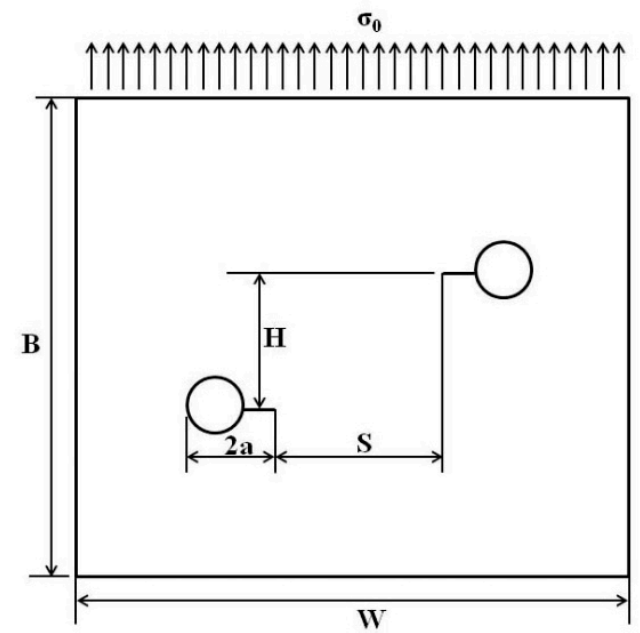

Figure 3. Geometry of a plate with two non-collinear through cracks.

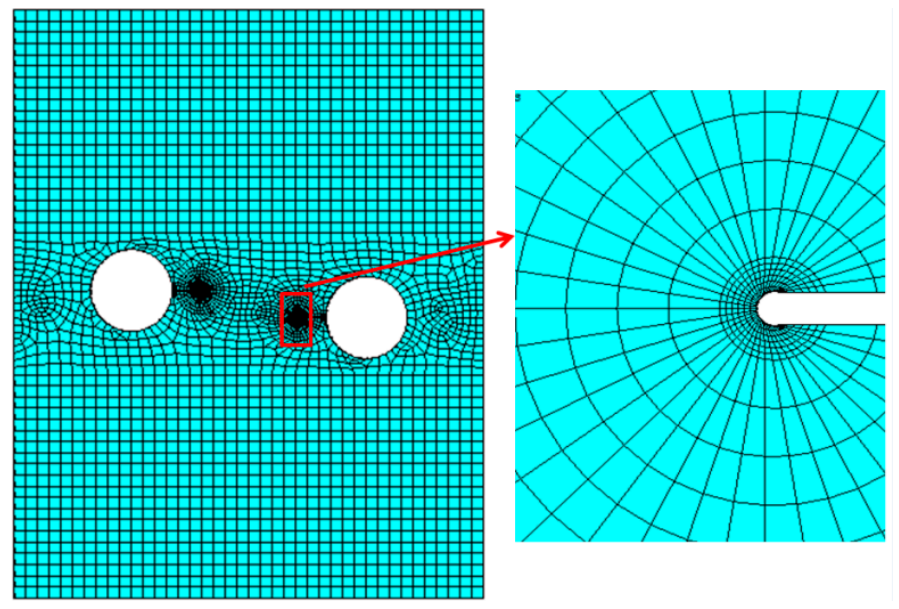

Figure 4. An example finite element mesh.

\section{Results and Discussion}

\subsection{Simulation Results of Stress Intensity Factor}

The finite element method was used to calculate the $K$ at the tip of the crack for different crack lengths. This method can derive the accurate $K$ by considering the cracks' interaction [22,23]. Figure $5 \mathrm{a}, \mathrm{b}$ and Figure 6 show the results of the mode I stress intensity factor range $\Delta K_{I}$, the mode II stress intensity factor range $\Delta K_{I I}$, and the equivalent stress intensity factor range $\Delta K_{\text {eq }}$, along with the crack propagation length $2 \mathrm{a}$, respectively. For the $\Delta K_{\text {eq }}$, several equations were presented under the I + II mixed mode load [24,25]. In this study, the equation put forward by Tanaka et al. [26] was used, which is defined as follows:

$$
\Delta K_{\mathrm{eq}}=\left[\Delta K_{\mathrm{I}}^{4}+8 \Delta K_{\mathrm{II}}^{4}\right]^{0.25},
$$

where $\Delta K_{e q}$ is the equivalent stress intensity factor range, $\Delta K_{I}$ is the mode I stress intensity factor range, and $\Delta K_{I I}$ is the mode II stress intensity factor range.

It can be seen from Figure 5a that the $\Delta K_{I}$ was increased with the increase of crack growth length 2a for the specimen A1 having a crack. Compared with the sample A1, the $\Delta K_{I}$ of specimens $\mathrm{H} 2.3$, H4.6, H6.9, and H9.2 with different crack offset distance was firstly increased until the inner crack tips of two cracks were overlapped, and then $\Delta K_{I}$ was decreased with the increase of the crack length owing to the shielding effect. It should be noted in Figure $5 \mathrm{~b}$ that the values of $\Delta K_{I I}$ were almost zero at first, when the two facing cracks were overlapped, and $\Delta K_{I I}$ was added gradually with the increase 
of the crack growth length. Although values of $\Delta K_{I I}$ were small compared with $\Delta K_{I}$, it could affect the crack growth directions. Moreover, $\Delta K_{I I}$ was gradually increased as the magnitude of overlapping was added owing to the interaction effect. The change trend of $\Delta K_{e q}$ versus 2a (Figure 6) was similar to that of $\Delta K_{I}$ versus 2a. The $\Delta K_{I}$ and $\Delta K_{e q}$ were increased firstly, and then decreased along with the crack length $2 \mathrm{a}$ in the region of overlap, finally reaching a very low value, which meant that the multiple crack growth rate for two non-collinear cracks with different crack offset was mainly dominated by $\Delta K_{I}$, even under the I + II mixed mode load.

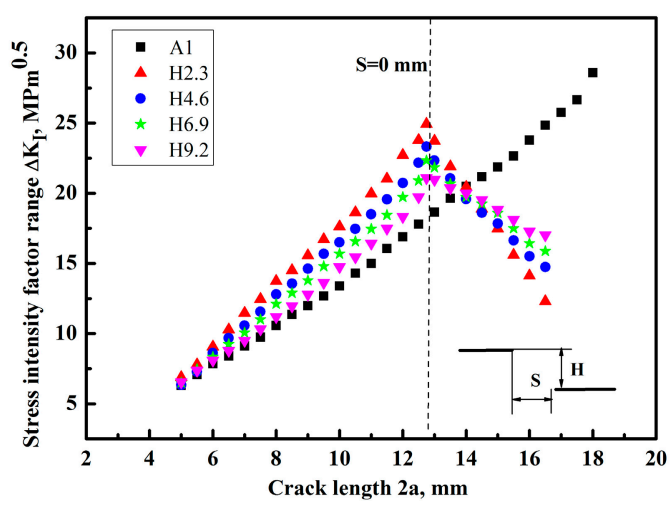

(a)

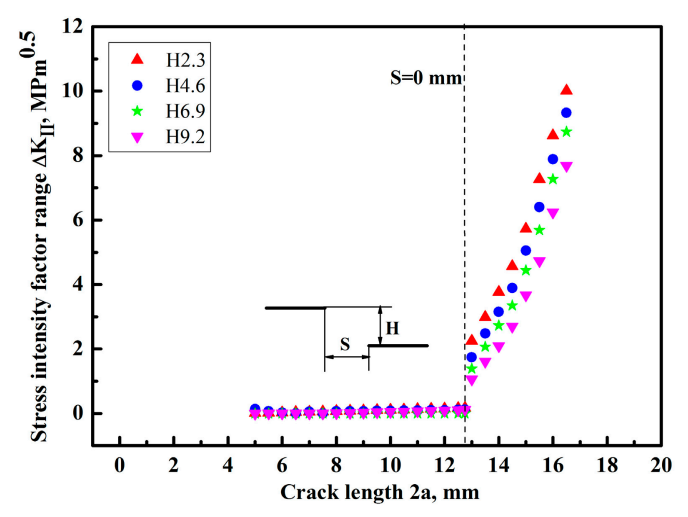

(b)

Figure 5. The stress intensity factor range (a) $\Delta K_{I}$ and (b) $\Delta K_{I I}$ changing with the crack growth length 2a.

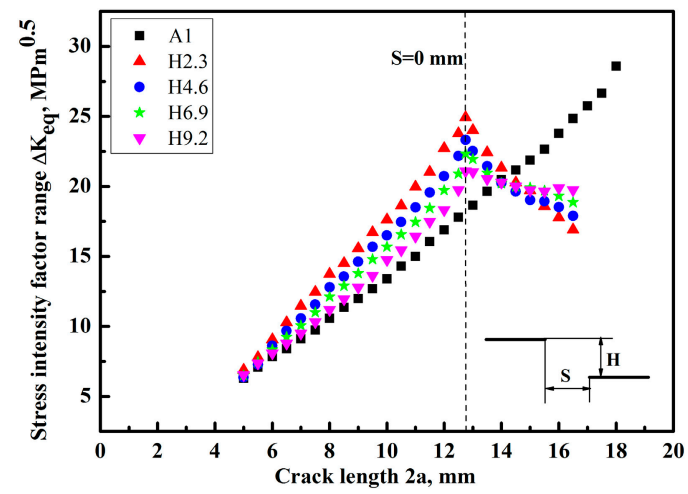

Figure 6. The $\Delta K_{e q}$ varying with the crack growth length 2a.

On the other hand, as shown in the case of H9.2, it had a relatively low stress intensity factor due to a large crack offset comparing with the specimens H2.3, H4.6, and H6.9, which was mainly attributed to the small interactions of cracks. For the sample H2.3 with relatively small crack offset, the values of $\Delta K_{I}$ and $\Delta K_{I I}$ were larger compared with other samples $\mathrm{H} 4.6, \mathrm{H} 6.9$, and $\mathrm{H} 9.2$ before the cracks crossed, which is because of the big interaction. For the specimens H2.3, H4.6, H6.9, and H9.2 with non-collinear cracks, the stress intensity factor at the overlapped position was greatly reduced owing to the negative interaction influence when the two cracks were overlapped, which could lead to the retardation of crack growth at the overlapped position. Moreover, the negative interaction is more pronounced with the increase of overlap degree due to the stress-shielding effect. Therefore, it can be concluded that the interaction effect changed from the positive interaction to the negative interaction during the process of cracks' growth.

\subsection{Multi-Cracks Fatigue Growth Path}

Crack growth paths for samples A1 having a single crack and samples H2.3, H4.6, H6.9, and H9.2 with different crack offsets of $\mathrm{H}=2.3 \mathrm{~mm}, 4.6 \mathrm{~mm}, 6.9 \mathrm{~mm}$, and $9.2 \mathrm{~mm}$, respectively, are shown in Figure 7. For sample A1, it can be found from Figure 7a that the new crack was initiated at the notch 
and grew perpendicular to the fatigue load. For the double non-collinear cracks, at the early stage of the crack propagation, the two cracks grew perpendicularly to the fatigue loading direction, similar to the specimen A1 with a single crack. However, when the cracks overlapped, the growth direction of two facing cracks began to change so that they were closed to each other, causing that the crack modes transfer from mode I to I + II mixed mode, as shown in Figure $7 \mathrm{~b}-\mathrm{e}$. Moreover, the curvature of cracks occurred not only affecting $K_{I}$, but also causing the increase of $K_{I I}$ around the crack fronts as the cracks grew. It was indicated when the double cracks approached one another, the stress states at the tip of crack would change as a result of the effect of the interaction. Therefore, during the process of the cracks' growth, the stress states changed from mode I to I + II mixed mode.

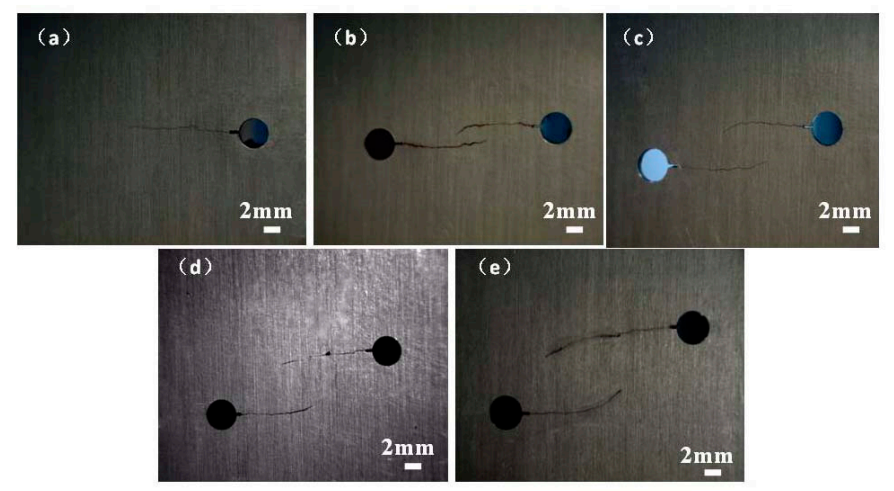

Figure 7. Crack propagation paths. (a) A1 with a single crack, (b) specimen H2.3 (initial condition: crack offset $\mathrm{H}=2.3 \mathrm{~mm}$ ), (c) specimen $\mathrm{H} 4.6$ (initial condition: $\mathrm{H}=4.6 \mathrm{~mm}$ ), (d) specimen $\mathrm{H} 6.9$ (initial condition: $\mathrm{H}=6.9 \mathrm{~mm}$ ), (e) specimen $\mathrm{H} 9.2$ (initial condition: $\mathrm{H}=9.2 \mathrm{~mm}$ ).

The fractured sample with a crack is displayed in Figure 8a and two non-collinear cracks with different crack offset distance $\mathrm{H}$ are presented in Figure $8 \mathrm{~b}-\mathrm{e}$. It can be found that the fracture pattern for specimens H2.3, H4.6, H6.9, and H9.2 with different crack offset distance is nearly similar, that is, firstly the mode I fracture and then the I + II mixed mode fracture. However, it is seen that the sizes of the remaining ligament between two cracks are added with the increase of crack offset $\mathrm{H}$. It is also seen that the crack growth length of two facing cracks was almost similar owing to the same initial notch lengths. When the crack deviation of adjacent crack tips begins to occur, the growth rates of two cracks will be decelerated because of the stress shielding effect. In all cases of the specimens with different $\mathrm{H}$, the double facing cracks did not merge until the sample was fractured, as seen in Figure 8b-e. That is, the cracks coalesced along with the rupture of the specimens.

\subsection{Multi-Cracks' Fatigue Growth Rate}

The relationship of crack growth rates $\mathrm{da} / \mathrm{dN}$ and the fatigue crack lengths $2 \mathrm{a}$ for specimens $\mathrm{H} 2.3$, H4.6, H6.9, and H9.2 compared with specimen A1 containing a crack was shown in Figure 9. It can be seen that the $\mathrm{da} / \mathrm{dN}$ were continuously increased with fatigue crack lengths for the specimen with a single crack. However, for specimens H2.3, H4.6, H6.9, and H9.2 with different crack offset distance $\mathrm{H}$, the da/dN were firstly increased, and then decreased with fatigue crack lengths. From Figure 9, it can be seen that when the crack length was greater than about $6.5 \mathrm{~mm}$, the crack growth rates of the samples H2.3, H4.6, H6.9, and H9.2 were faster than that of the specimen A1 containing a single crack in the middle and late stages during the crack steady growth process, which means that the presence of multiple cracks accelerated the da/dN of samples H2.3, H4.6, H6.9, and H9.2. Even for $\mathrm{H} 9.6$ with the greater $\mathrm{H}$, the da/dN was faster than that of the specimen $\mathrm{A} 1$ containing a single crack. Also, when the $\mathrm{H}$ became small, the acceleration effect became large. However, when the inner crack tips of the double facing cracks were overlapped-and at this moment, the two facing cracks began to change their growth direction-it can be observed from Figure 9 that the da/dN of samples H2.3, H4.6, H6.9, and H9.2 were reduced greatly owing to the decreased driving force of crack growth caused 
by the cracks' shielding effect. In this case, the retarding effect of crack propagation exceeded the acceleration effect, and the effect of interaction on crack propagation varied from positive to negative. Furthermore, the shielding effect became greater with the increase of overlapping extent, which caused the lower crack grow rate. This suggests that, owing to the change of interaction effect, the effect of cracks interacting on multiple crack growth behaviour should be evaluated by considering the whole process of crack propagation for non-collinear cracks with different crack offset $H$. Thus, the influence of interaction on multiple cracks' growth behaviour depended greatly on the different stages of crack propagation. Therefore, this study could provide the theoretical basis and technical references for fatigue life prediction and the safety assessment of components containing non-collinear multi-cracks.
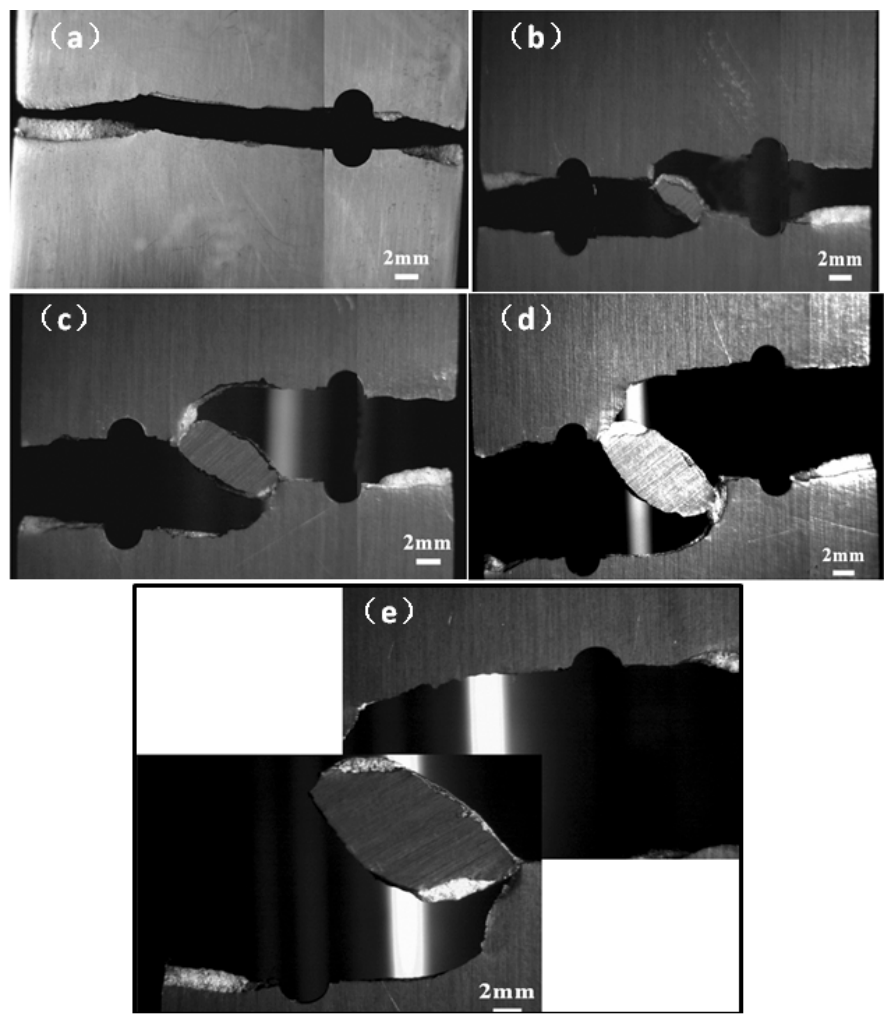

Figure 8. The fractured specimens for (a) A1 with a single crack, (b) specimen H2.3 (initial condition: crack offset $\mathrm{H}=2.3 \mathrm{~mm}$ ), (c) specimen $\mathrm{H} 4.6$ (initial condition: $\mathrm{H}=4.6 \mathrm{~mm}$ ), (d) specimen $\mathrm{H} 6.9$ (initial condition: $\mathrm{H}=6.9 \mathrm{~mm}$ ), (e) specimen $\mathrm{H} 9.2$ (initial condition: $\mathrm{H}=9.2 \mathrm{~mm}$ ).

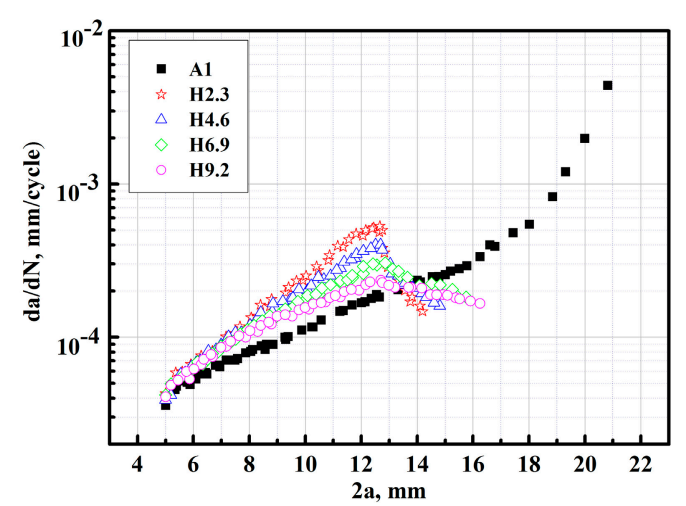

Figure 9. The crack propagation rates plotted with fatigue crack length for specimens H2.3, H4.6, H6.9, and H9.2 compared with specimen A1. 


\section{Conclusions}

The influence of the interaction on multiple cracks' fatigue growth behaviour for the specimens with different crack offset compared with the specimen containing a single crack was studied by experimental and numerical investigations. The conclusions are as follows:

(1) The double non-collinear cracks could change their growth direction when the two cracks were close to each other, leading to the change of load mode from mode I to I + II mixed mode as a result of the interaction. Moreover, $\Delta K_{I I}$ affecting the growth directions of the crack tip was gradually increased as the magnitude of overlapping was added.

(2) Finite element analysis shows that the $\Delta K_{I}$ and $\Delta K_{e q}$ of specimens with different crack offset were reduced greatly when the two cracks were overlapped, and the specimens with a large crack offset distance have a relatively low $\Delta K_{I}$ and $\Delta K_{e q}$, owing to a small interaction. $\Delta K_{I}$ and $\Delta K_{e q}$ are the main parameters of the crack growth driving force, and the experimental results of crack growth rate have a similar change trend to that of $\Delta K_{I}$ and $\Delta K_{e q}$ by numerical analysis.

(3) The cracks' interaction has a positive or negative effect on the stress intensity factor of specimens with two non-collinear cracks, which depended on the relative position of the two cracks, thus leading to the acceleration or deceleration of crack growth rate compared with the specimen with a single crack.

Author Contributions: Conceptualization, H.J.; methodology, B.C.; software, L.M.; validation, L.M.; formal analysis, H.J.; investigation, H.J.; resources, B.C.; data curation, B.C.; writing-original draft preparation, H.J.; writing-review and editing, H.J. and B.C.

Funding: This research was funded by National Ministry of Industry and Information Technology Project, grant number M J-F-2011-34.

Conflicts of Interest: The authors declare no conflict of interest.

\section{References}

1. Bolivara, J.; Frégonèsea, M.; Réthoréb, J.; Duret-Thualc, C.; Combraded, P. Evaluation of multiple stress corrosion crack interactions by in-situ Digital Image Correlation. Corros. Sci. 2017, 128, 120-129. [CrossRef]

2. Xu, Y.W.; Jing, H.Y.; Xu, L.Y.; Han, Y.D.; Zhao, L. Stress corrosion cracking characteristics of CF8A austenitic stainless steels and interactions between multiple cracks in a simulated PWR environment. Constr. Build. Mater. 2019, 203, 642-654. [CrossRef]

3. Silva, L.F.M.; Gon, A.; Oliveira, F.M.F. Multiple-site damage in riveted lap-joints: Experimental simulation and finite element prediction. Int. J. Fatigue 2000, 22, 319-338.

4. Heider, C.A.; Edson, D.L. The multiple fatigue crack propagation modelling in nonhomogeneous structures using the DBEM. Eng. Anal. Bound Elem. 2019, 98, 296-309.

5. Marcello, L.; Filippo, B. On the fatigue propagation of multiple cracks in friction stir weldments using linear and non-linear models under cyclic tensile loading. Eng. Fract. Mech. 2019, 206, 463-484.

6. Hussam, M.; Akshat, C.; Guillermo, R. Fatigue and fracture life-cycle cost assessment of a Miter gate with multiple cracks. Eng. Fail. Anal. 2018, 83, 57-74.

7. Hakan, D.; Ayhan, A.O. Non-planar crack growth analyses of multiple cracks in thin-walled structures. Int. J. Fatigue. 2016, 92, 596-604.

8. Dündar, H.; Ayhan, A.O. Three-dimensional fracture and fatigue crack propagation analysis in structures with multiple cracks. Comput. Struct. 2015, 158, 259-273. [CrossRef]

9. Amit, K.S.; Arora, P.K.; Harish, K. Numerical and experiment fracture modeling for multiple cracks of a finite aluminum plate. Int. J. Mech. Sci. 2016, 110, 1-13.

10. Zhu, S.P.; Hao, Y.Z.; Liao, D. Probabilistic modeling and simulation of multiple surface crack propagation and coalescence. Appl. Math. Model. 2019. [CrossRef]

11. Kikuchi, M. Study on multiple surface crack growth and coalescence behaviors. AIMS Mater. Sci. 2016, 3, 1623-1631. [CrossRef]

12. Yan, X.; Miao, C. Interaction of multiple cracks in a rectangular plate. Appl. Math. Model. 2012, 36, 5727-5740. [CrossRef] 
13. Zhao, J.F.; Zhao, Q. A method for stress intensity factor calculation of typical MSD configurations. Adv. Mater. Res. 2013, 700, 149-152. [CrossRef]

14. Han, Z.C.; Qian, C.F.; Tang, L.Q.; Li, H.F. Determination of the enhancement or shielding interaction between two parallel cracks under fatigue loading. Materials 2019, 12, 1331. [CrossRef]

15. Zhao, J.F.; Xie, L.; Liu, J.; Zhao, Q. A method for stress intensity factor calculation of infinite plate containing multiple hole-edge cracks. Int. J. Fatigue 2012, 35, 2-9. [CrossRef]

16. Jin, H.J.; Su, J.W. A new driving force parameter for fatigue growth of multiple cracks. Int. J. Fatigue 2017, 96, 10-16. [CrossRef]

17. Yao, A.; He, W.; Xu, T.; Jiang, H.; Gu, D.F. 3D-VCCT based fracture analysis method for gas pipelines with multiple cracks. Nat. Gas Ind. B 2019, 6, 488-496. [CrossRef]

18. Lie, S.T.; Zhao, H.S. Fracture analysis of load-carrying cruciform fillet welded joints with multiple cracks. Eng. Fract. Mech. 2018, 193, 32-46. [CrossRef]

19. Kamaya, M. A crack growth evaluation method for interacting multiple cracks. JSME Int. J. Ser. A 2003, 46, 15-23. [CrossRef]

20. ABAQUS. Standard User's Manual Ver. 6.5; ABAQUS Inc.: Pawtucket, RI, USA, 2005.

21. Courtin, S.; Gardin, C.; Bezine, G.; Ben, H.H.H. Advantage of the J-integral approach for calculating stress intensity factors when using the commercial finite element software ABAQUS. Eng. Fract. Mech. 2005, 72, 2174-2185. [CrossRef]

22. Shu, Y.X.; Li, Y.Z.; Duan, M.; Yang, F. An X-FEM approach for simulation of 3-D multiple fatigue cracks and application to double surface crack problems. Int. J. Mech. Sci. 2017, 130, 331-349. [CrossRef]

23. Carpinteri, A.; Brighenti, R.; Vantadori, S. A numerical analysis on the interaction of twin coplanar flaws. Eng. Fract. Mech. 2004, 71, 485-499. [CrossRef]

24. Sih, G.C. Strain-energy-density factor applied to mixed mode crack problems. Int. J. Fract. 1974, 10, 305-321. [CrossRef]

25. Richard, H.A.; Fulland, M.; Sander, M. Theoretical crack path prediction. Fatigue Fract. Eng. Mater. 2005, 28, 3-12. [CrossRef]

26. Tanaka, K. Fatigue crack propagation from a crack inclined to the cyclic tensile axis. Eng. Fract. Mech. 1974, 6, 493-507. [CrossRef] 